\section{Action on academic pay}

SIR - Paramount among the perceived managerial inadequacies of Britain's vice-chancellors and principals has been their failure, as leaders, to maintain the morale and retain the respect of their most important corporate asset - the academic teaching and research staff without whom a university does not exist. As a scientist, I feel qualified to comment only on the science-based disciplines, although I am sure that my arts colleagues would wish to argue a similar case. Science-based academic staff have two main functions in a modern technology-dependent society: (1) to teach and train tomorrow's innovators, engineers, industrial scientists, doctors, surgeons and the rest to the very highest levels and (2) to carry out fundamental new and often patentable research in competition with the best scientists from other countries. Both functions are recognized by most countries to be of unquestionable importance to the future economic and cultural wellbeing of nations. Britain's university academics can be proud of their record of producing first-class graduates and PhD-level scientists, engineers and doctors. Indeed, our products are usually in advance of foreign competition not only with respect to the standard reached, but also achieving that standard (BSc at 21 or $\mathrm{PhD}$ at 24) a year or more earlier than their counterparts elsewhere.

What has been the reward for the teaching and research staff of Britain's universities for this dedication and productivity and for the maintenance of the highest quality of advanced education and research over the past decade? In its publication The State of the Universities (1991), the Committee of ViceChancellors and Principals (CVCP) admits that the salaries of its academic staff have fallen over a ten-year period relative to comparable groups of workers by some $25-30$ per cent. It does not make mention of the fact that it has itself been setting priorities and limiting those salary rates over the same period. This is only the UK position, and comparison with international colleagues shows UK university teachers and researchers to be at least 30 per cent worse off, depending on grade, in real terms. For those of us who, despite the obvious attractions elsewhere, would prefer to serve our own country's benefit, we must protest at this shabby treatment of public servants. This position has been 'achieved' by the CVCP limiting pay increases to academic and related staff, often to several percentage points below the rate of inflation, year on year over that period. The CVCP is thus failing to provide a work environment that would enable young scientists and engineers to conclude that there is any value in sacrificing three, six or even nine years of their lives to training for a worthwhile professional career at the end of that period. The highly predictable effects are now being felt with a vengeance. Young, high quality UK staff and research students are increasingly difficult or in some cases impossible to recruit, and the morale and enthusiasm of those alredy in post is at rock bottom. In addition, young research staff at the postdoctoral level (24-28 years old) see few tenure prospects beyond their fixedterm contracts, the only certainty of which is a guaranteed termination of contract usually after one, two or at most three years. High-quality takers for these positions, the seedcorn of future industrial as well as academic research and innovation, are becoming few and far between.

The potential and indeed actual acceleration of the brain-drain of economically important assets should be obvious, but not, it would appear, to our leaders, nor indeed to the government. Despite the obvious dangers, the vice-chancellors and principals have contrived year after year to hold down academic salaries as the simplest way of 'managing' the universities and complying with decreasing government funding. The CVCP says it has insufficient funds both to make reasonable pay awards and to fund the infrastructure, building maintenance, expansion and so on. The government says the universities are not underfunded. Someone is clearly not telling the truth.

Much of our problem appears to be due to the reluctance of the CVCP to argue the case vigorously for fair rewards for Britain's academic teachers and researchers, both with the public and with government. One suspects that all the publicity and impact gained by the CVCP over the past ten years to show the plight of the universities would probably not match in total the few days of publicity surrounding the recent 'defection' to the United States of the Alzheimer's research team from Imperial Medical School (St Mary's).

The CVCP is failing in its duties to key staff, and in so doing is destroying the whole ethos of advanced teaching and research as a career that young people will be interested in joining. It has now well demonstrated and even acknowledged its inability, for whatever reason, to maintain let alone increase the standard of living of university teachers and researchers, even compared to teachers at the much less advanced school level. The time is well overdue for the CVCP to stand down from the pay negotiating process, and to call for an independent pay review body for university academic and related staff a body that the government has already granted to the school-teaching profession. At this time of year, the university pay negotiations should be well advanced, with a settlement due on 1 April, but previous experience suggests that this will not happen. A more likely scenario is protracted 'negotiations', a request for more funding from government, followed by a pay award several per cent below the rate of inflation, paid six to nine months late. A best guess on the turn of events is that rather than attempting to redress the balance of decline over the past decade, it will currently be considering whether it can secure a figure of 2-3 per cent for this year's pay award. There are additional small merit awards for a few, and I have been the fortunate recipient on occasion, but the vast majority of highly qualified worthy individuals do not normally receive these. It is these people who deserve a fair deal, and in view of the school teachers' basic award of 7.5 per cent, payable from 1 April, there can be absolutely no justification for anything less as a basic award for university teachers also.

I respectfully suggest that the $\mathrm{CVCP}$ should withdraw from pay negotiation activities immediately, calling as it does so for an Independent Pay Review Panel. Time is of the essence if the rot is to be stopped before it does more harm and costs the government very real money to correct. This action by the CVCP would initiate the long haul back to a fair and worthwhile academic teaching and research career structure for our young scientists and engineers, something that is of crucial importance to the future economy of this country.

HOWARD R. MORRIS

Imperial College,

Wolfson Laboratories,

Department of Biochemistry,

London SW72AY, UK

\section{Power and money}

SIR - I read with interest the letter by my Italian colleagues (Nature 355, 290; 1992) who inform your readers of their grant of L35,000 million from what they call the Italian Electric Power Authority to study air pollution and health.

Like nearly everybody else in academic life, we are short of money and have been told by our administration that we will be asked to pay part of the electricity bill out of our research money. Electric power in Italy is very expensive: now I understand why.

MARCO FRACCARO

Biologia e Genetica Medica,

Università di Pavia, Italy 